\title{
Article
}

\section{On the Concept of Corporate Culture}

\author{
Prof. Dr. Hans Strikwerda*
}

\section{Introduction}

The Dutch Corporate Governance Code, published in 2016, stipulates in its Principle 2.5 that the executive board is responsible for creating a culture aimed at longterm value creation by the firm and that the supervisory board is tasked to monitor the actions implemented for this by the executive board. ${ }^{1}$

In the best practice 2.5.1, the Code stipulates that the executive board defines values for the firm that contribute to a culture aimed at long-term value creation, to be discussed with the supervisory board. In the same best practice, it is stipulated that the executive board stimulates behaviour that matches these values and that the executive board sends a message to the organisation with respect to these values by demonstrating exemplary behaviour.

In best practice 2.5.4, the Code stipulates that the executive board must give account on culture by reporting on the values and the way these are embedded in the organisation of the firm.

The Dutch Corporate Governance Code is mandatory for public corporations, but the courts, including the Dutch Supreme Court, tend to take the Code also as a standard for good practice in business administration in all other cases.

The Dutch Corporate Governance Code 2016 moves the phenomenon of corporate culture from the domain of informal administrative instruments to the domain of the legal aspects of business administration. The phe-

Prof. Dr J. Strikwerda, University of Amsterdam.

1. It must be noted that in the Code, prior to culture in best practice 1.1.1 the Code stipulates that the executive board develops a vision for longterm value creation and defines a strategy consistent with that vision. To comment on this best practice is outside the scope of this article. nomenon of corporate or organisational culture has always been part of the doctrine of business administration since this doctrine was formulated by Henry Fayol in 1918, be it under the label of esprit de corps. ${ }^{2}$

The phenomenon of corporate or organisational culture became more emphasised in the 1970s, based on the work of Margaret Mead, initially as part of the field of organisational behaviour to facilitate the necessary further economic decentralisation and flexibility in organisations, but shifting in the 1980s into the function of coordination in an unconscious response to the decline of the effectiveness of formal instruments for command and control, which is due to the growing role of intangible assets. In this change of the role of corporate culture also its definition has changed and still is changing, as is the phenomenon of culture and its roles and effects. Especially the phrase 'culture' is one of those terms in our society at large, which is subject to the phenomenon of simulacra (Baudrillard), that is, it does not refer to an existing reality, but people define culture in an individual subjective or small group consensus, for themselves in their own situation. Due to the phenomenon of the echo-chamber effect, many people tend to think to understand what is meant by culture because, e.g. through social media, they have seen the phrase before, without being aware of the provenance of the concept. ${ }^{3}$ At the same time the original meaning of culture, the collective programming of the mind of the (new) members of a group, with respect to what is acceptable behaviour or not, what works or not to achieve ends, etc. is questioned in a complex, multi-ethnic society with hyphenated identities, individuals sporting multiple identities, multiples lifestyles, professional training and developing talent due to the urbanisation of society,
2. Fayol H. (1918/1999). Administration Industrielle et Générale. Paris: Dunod.

3. Pentland A. (2014). Social Physics: How Good Ideas Spread - The Lessons from a New Science. New York: The Penguin Press. 
with an emphasis on innovation and open business models. Increasingly individuals are part of multiple cultures, ${ }^{4}$ of which the corporate culture is one, and the concept of organisational culture needs to be understood in an environment of job-hopping, combining multiple jobs, self-employment, absence of lifetime employment and professional education.

The author of the Dutch Corporate Governance Code, the Monitoring Commission, projects the following meanings in 'culture':

- Desirable behaviour in view of long-term value creation

- Integrity in carrying on a business

- Trust

- Safety (a safe psychological climate)

- The values that implicitly and explicitly guide behaviour and acts

Thus understood, mixing means and ends, the phenomenon of corporate or organisational culture as a legal requirement of business administration, especially if used to test the duty of care, risks to be a source of differences of opinions between various stakeholders or possibly even conflicts. Especially the question is to be raised whether an executive board can exculpate itself from claims of mismanagement by showing to have worked on the culture as suggested in the Code.

To contribute to a clarification of this question, in this article we will explain the nature of culture as it is developing, the nature of value, the mechanism that explains the creation of a culture, and the relationship between culture and long-term value creation as well the relationship between culture and behaviour.

\section{What Is (Corporate) Culture?}

The original definition of culture is 'the collective programming of the mind': 5

- Based on a pattern of shared basic assumptions; on markets, customers, institutional environment, motivation of management and workers, technology, causal relations, etc. (epistemic values);

- Which are learned by a group as it solves its problems of external adaptation and internal integration (coordination);

- Which are codified in systems, processes, procedures, norms etc. of the group;

- Which have worked well enough to be considered valid; and, therefore,

4. Fligstein N. \& McAdam D. (2012). A Theory of Fields. New York: Oxford University Press.

5. Based on: Hofstede G. H. (1980). Culture's Consequences: International Differences in Work-Related Values. Beverly Hills, CA: Sage Publications; Schein E. H. (2010). Organizational Culture and Leadership. San Francisco, CA: Wiley; Prahalad C. K. \& Krishnan M. S. (2008). The New Age of Innovation: Driving Cocreated Value through Global Networks. New York: McGraw-Hill.
- Are to be taught to new members (including the selection and deselection of members) as the correct way to perceive, think, feel in relation to those problems.

Culture so defined has two dimensions: it is a process of socialisation and culture is about transfer of knowledge (epistemic values) and norms. Both culture as a process and culture as a container of content, varies across national cultures, ethnic groups, and time periods.

Corporate culture has multiple functions: ${ }^{6}$

- Culture defines the social boundaries of the group or organisation

- Culture provides a distinction and identity to the members of a group

- Culture makes the loyalty of individuals to a common purpose possible

- Culture provides social stability and social and psychological safety

- Culture is a (cybernetic type of) control mechanism that provides purpose and meaning to thinking and behaviour.

The last function in this list, in combination with the insight of cybernetics that for survival in a changing environment the organisation needs the capability of adaptation and transformation, it follows what the Greek philosophers understood when writing on the role of education (which is part of the process of culture) in society: the innovative reproduction of society. So, for culture; for survival of the group, respectively long-term value creation in an age of disruption, culture is not simply about copying existing epistemic values, other values, traditions, etc. to new generations, it is as much about reproducing the capability of reinterpreting, reconceptualising, reframing a changing world, the capability to acquire and develop new knowledge to ensure continuity of an organisation and its identifying mission and final values.

The original definition of corporate culture by psychologist Edgar H. Schein includes three layers of organisational culture: the lowest level is that of basic assumptions about causal relations, about the nature of man, social relations, etc. These basic assumptions were assumed to be unconscious or preconscious and used not to be subject of discussion or being questioned. The second level is that of values, norms, as expressed in stories being told in the group, myths, and serve to legitimise decisions and behaviour. The third level of culture was assumed to be that of visible signs of culture, organisation structure, symbols of power, visible and audible behaviour, in which the two other levels are codified. ${ }^{7}$ In order that the firm is in-control, as defined in cybernetics and in the resource-based (dependency) view of

6. Greenberg J. \& Baron R. A. (2003). Behavior in Organizations: Understanding and Managing the Human Side of Work (8th ed.). Upper Saddle River, NJ: Prentice-Hall; Robbins S. P. (2003). Essentials of Organization Behavior (7th ed.). Upper Saddle River, NJ: Prentice Hall.

7. Schein E. (1985). Organizational Culture and Leadership. University of Illinois at Urbana-Champaign's Academy for Entrepreneurial Leadership Historical Research Reference in Entrepreneurship. 
the firm, precisely requires that the basic conditions, that is a basic worldview on continuously changing causal relations in the economy, are revised, expressed in new, innovative business models to achieve long-term value creation. ${ }^{8}$ This questions the lowest level in Schein's concept of organisational culture.

As the concept of organisational culture to a large extent was an intuitive response to the declining effectiveness of the traditional command and control hierarchy, a second largely intuitive response came into being with respect to the static nature of Schein's definition of organisational culture. As a result, the definition of organisational culture tended and tends to be limited to values and behaviour, ${ }^{9}$ while in the context of the then prevailing subjectivism of postmodernism in the $1980 \mathrm{~s}$ and 1990 s, it was permissible to use virtually any definition of culture.

As a consequence, today culture serves as a container phrase for:

1. Meaning, mission, purpose

2. Values
a. Final values
b. Instrumental values
c. Epistemic values
d. Subjective values
e. Objective values
f. Target values
g. Limit values or norms
h. Pro tanto values
i. All-considered-well values

3. Integrity

4. A cognitive definition of culture, the programming of thinking by transfer of knowledge

5. A behaviourist definition of culture, the programming of thinking of individuals through rewards and punishment

6. Identification of individuals with the mission, the values, the products, markets, customers of the firm

7. Pro-active behaviour, self-coordination, self-organisation, contributing bottom-up initiatives

8. Trust, identification-based trust, institutional trust, interpersonal trust, trust as reduction of complexity

9. The psychological climate in the organisation ${ }^{10}$
a. The degree of orientation on format rules
b. The psychological distance between managers and workers
c. Creativity and the willingness to innovate
d. Whether it is permissible to question authority and decisions

8. Beniger J. R. (1986). The Control Revolution: Technological and Economic Origins of the Information Society. Cambridge, MA: Harvard University Press; Fligstein N. (1990). The Transformation of Corporate Control. Cambridge, MA: Harvard University Press; Pfeffer J. \& Salancik G. R. (2003). The External Control of Organizations: A Resource Dependence Perspective. Stanford, CA: Stanford Business Books.

9. Deal T. E. \& Kennedy A. A. (1982). Corporate Cultures: The Rites and Rituals of Corporate Life. Reading, MA: Addison-Wesley.

10. Psychologist Schein sees psychological climate not as part of culture, but through the factors sociability and solidarity the distinction between culture and psychological climate is fluid. e. Sociability (the degree to which the members of the organisation have friendship relations)

f. Solidarity (The degree of a shared understanding of tasks and objectives)

g. An orientation on society

h. Whether rewards are being applied rather than punishments

10. An organic organisation (as opposed to a mechanical organisation)

Each of these elements, usually in some combination with others, is of importance for the performance and continuity of a firm. The majority of these elements are to be achieved through the application of formal administrative instruments shaping the organisation as a systemic context for managers and employees.

The field of organisational behaviour teaches through the Interactionist Perspective Model that the behaviour of individuals results from two influences: personal attributes (those which are genetically defined, those which are acquired by socialisation, education and training) and the characteristics of the systemic context (set targets, attributed decision rights, assessment criteria, pay systems, career paths, access to information, decision support systems (in which values are codified)), and that for most people the systemic context is more defining their behaviour than are their personal attributes. ${ }^{11}$ That is, culture, nor values, defines or guides behaviour in a direct way, but through a material context, including that for most people knowledge is what is being defined as knowledge in their relevant social group. This, with the exception of identification, is an individual psychological internalisation process and sociability, which is part of the system of social control (aka informal organisation).

\section{The Relationship between Culture and Long-Term Value Creation}

The Code assumes a relationship between the organisational culture of a firm and long-term value creation. The author of the Code, the Monitoring Commission, does not explain or validate this relationship. In view of, e.g. the resource dependency view of the firm, the question that must be asked is whether culture alone suffices. It must be noted, however, that the Code not only emphasises culture as a factor for long-term value creation, the Code also mandates in best practice 1.1.1 that the executive board develops a vision on long-term value creation and a strategy to achieve this. In best practice 3.1.2, the Code stipulates that in the remuneration of the members of the executive board, it needs to be

11. Greenberg J. (2010). Managing Behavior in Organizations (5th ed.). Upper Saddle River, NJ: Prentice Hall, p. 70. 
taken into account whether the executive board has performed a scenario planning.

A reasonable academic research exists on what contributes to long-term value creation and on whether firms focused on long-term value creation are financially more successful compared to firms focused on short-term profit maximisation. ${ }^{12}$

Characteristics of firms that are successfully in longterm value creation are:

1. A tolerant style of leadership and administration with a tenacity on final values with respect to the role of the firm in society. This tolerance includes a sensibility for weak signals with respect to changes in the environment, and loose control and loose programming allowing workers to experiment to find answers to new demands from the market.

2. Maintaining an organic organisation as opposed to a mechanical organisation, in which the emphasis is on the role of knowledge, not on formal positions, and employees are stimulated to participate in external knowledge ecologies, employees are perceived as self-motivating and capable of self-organisation to complete formal assignments. ${ }^{13}$

3. Information is organised in one, not-fragmented, information space, disembedded from the structure of the internal organisation of the firm, accessible for all managers and employees (elimination of vertical and horizontal information asymmetry). This information space also provides fast feedback information, allowing for trial-and-error in order to be in-control in dynamic, unpredictable environments. Also, systems for management information are not based on those for accounting information (whereas the Code only mentions accounting information).

4. Conservatism in financing the firm, no promise is being made for a guaranteed level of dividend payments. Profit is seen as resulting from activities well done, not as an objective.

5. The firm is seen by the executive board not as a profit machine but as a constituent institution in society, providing stability in society, including sustainability both for the social and for the physical environment.

6. A sufficient level of investments in R\&D and especially a sufficient level of investments in human capital. Investments in human capital are not only on knowledge and skills, but also, e.g. through management development programmes as opposed to leadership programmes, on new concepts, on a growth of conceptual complexity to foster preparedness and adaptability.

7. Time, money and energy is spent on scenario planning. That is, the question is being asked what are the most fundamental uncertainties for the firm, what might happen with which consequences for the firm and how to prepare for this. Scenario-planning is aimed at changing the worldview of managers.

8. A sound balance exists between exploration and exploitation, which can be inspected through the allocation of resources for short-term performance and long-term performance, the applied method of strategy execution (which prioritises investments in intangible assets), the nature of management information and the nature of performance parameters used (non-financial). ${ }^{14}$

The question to be answered is what these eight characteristics tell us about the relationship between culture and long-term value creation. Of these eight characteristics there are two (numbers one and two) which can be related directly to culture. The first characteristic, a tolerant style of leadership with a tenacity on final values, implies that it all starts or is maintained by the personality of the CEO, his or her image of man and his or her worldview. This is prerequisite for the seven other factors. In terms of administrative instruments however, this is not about culture, but it is about the challenge for the supervisory board to identify, select, appoint and assess the right person for the position of CEO, and not letting itself being trapped in the perfect agent syndrome. ${ }^{15}$ This is an inalienable responsibility of the supervisory board to assure the first prerequisite for a long-term value creation. The right CEO, as we will see further on, in terms of style of leadership, is essential for creating and maintaining a proper culture.

The concept of the organic organisation is closest to the concept of culture as expressed in the various subjective definitions of culture. In terms of values, the main characteristics of the organic organisation is an emphasis on final values, expressed in an orientation on society, expressed in a mission stating which value the firm contributes to which domain in society, and in which employees are seen as ends in themselves, that is Kant's final value, not as instruments. With respect to instrumental values, the emphasis is on knowledge, both as a basis for authority to make decisions, that is not on formal positions, and the emphasis is on acquiring new
12. De Geus A. (1997). The Living Company. Boston, MA: Harvard Business School Press; Kanter R. M. (2011). How Great Companies Think Differently. Harvard Business Review (November); Lévy M., Eskew M., Bernotat W. H. \& Barner M. (2007). Who Owns the Long Term? Harvard Business Review (July-August).

13. The characteristics of the organic organisation and its positive effects on innovation and long-term survival were first identified by Burns \& Stalker in 1963; these characteristics are corroborated in recent research; the specifics can be found in, e.g. Huczynski A. A. \& Buchanan D. A. (2007). Organizational Behaviour (6th ed.). Harlow, England: Financial Times-Prentice Hall, p. 562.
14. March J. G. (1991). Exploration and Exploitation in Organizational Learning. Organization Science, 1, 71-87; Kaplan R. S. \& Norton D. P. (1996). The Balanced Scorecard: Translating Strategy into Action. Boston, MA: Harvard Business School Press; Kaplan R. S. \& Norton D. P. (2008). The Execution Premium: Linking Strategy to Operations for Competitive Advantage. Boston, MA: Harvard Business Press.

15. Jensen M. C., \& Meckling W. H. (1998). The Nature of Man. In M. C. Jensen (Ed.), Foundations of Organizational Strategy. Cambridge, MA: Harvard University Press. 
knowledge from outside, fostering innovation and adaptation, that is not an emphasis on tradition or routines. ${ }^{16}$ However, final values are not only part of the culture of the organisation (as in the formal definition of culture), but are first and foremost all elements in the constitution of the firm, specified in a formal document, e.g. in a by-law. These final values need to be codified in all systems, processes, procedures and decision criteria in the organisation of the firm. Amongst others in the selection and deselection criteria for executives, managers and employees. This codification is an inalienable responsibility of the executive board, to be monitored by the supervisory board.

It is to be expected that the final, constitutional values are transferred through organisational socialisation processes and through formal systems to (new) members of the organisation, but members of the organisation only can internalise these values as far these are congruent with their own personal values; the organisation should not impose values on (new) members as this will result in resistance to control and accountability avoidance. ${ }^{17}$ Individuals having personal values too inconsistent with the constitutional values of the firm need to be deselected. Where the Code (best practice 2.5.1) stipulates that the executive board is responsible for the embedding and maintenance of the values of the firm, it should read 'codification and application'. In the same best practice, the Code suggests that the executive board is tasked to stimulate behaviour consistent with the (final) values and propagates these values through exemplary behaviour. From the field of business administration, especially the subfield 'management and organizational behavior', it is well known, and actually a best practice, that executives are tasked to facilitate required behaviour, which implies that specific decisions are required with respect to the design and operations of the formal organisation, which can be observed objectively by the supervisory board in their task to monitor the executive board with respect to creating an organisation for longterm value creation. The issue of exemplary behaviour introduces the next section, how to shape and change the culture of an organisation.

There is not a simple relationship between culture and long-term value creation, the phenomenon of culture needs to be unpacked and codified in the organisation as a systemic context.

\section{Shaping and Changing the Culture of an Organisation}

An extensive academic literature, based on empirical research, exists on how organisational culture is being

16. Mullins L. J. (2007). Management and Organisational Behaviour (8th ed.). London: Prentice-Hall, p. 610-612

17. Rollinson D. \& Broadfield A. (2002). Organisational Behaviour and Analysis: An Integrated Approach (2nd ed.). New York: Prentice Hall Financial Times, p. 552-558. created, shaped and changed. Obvious is the role of the founder of the firm, if this is a person of societal values and visions, often expressed in the quality of products or services. In absence of the founder other mechanisms have been identified maintaining and shaping culture. Understandably, in behavioural sciences different insights exist, depending on basic assumptions with respect to human behaviour. Two main schools for culture shaping and changing can be discerned, the behaviourist school and the cognitive psychology school. The first school, of which the main representative is the psychologist Edgar H. Schein, assumes that behaviour of individuals is guided by rewards and punishment, including the need for belongingness and fear of being expelled from a relevant group. As a consequence, Schein defines a number (12) of embedding mechanisms to be used by the executive board to shape and change culture. The first embedding mechanism is what leaders (consistently and persistently) pay attention to, measure, and control. For example, if the executive board of a hospital determines that clinical quality is the first value, all internal reporting forms must have clinical quality in the first line, all agendas for interactive control should have clinical quality as the first agenda item, not financial aspects. ${ }^{18}$

Another embedding mechanism is the observed criteria by which leaders allocate scarce resources. These two mechanisms are related directly to long-term value creation; focussing on short-term profits or on strategic development, allocating resources to exploitation or to exploration.

Another behaviourist embedding mechanism for shaping and changing culture is the observed criteria by which leaders recruit, select, promote, retire and excommunicate members of the organisation. These three are primary embedding mechanisms, which require consistent and persistent behaviour of top-management and lower management in daily decision-making. Secondary are a number of articulation and reinforcement mechanisms, like organisation design and formal statements or organisational philosophy, values, and creed. ${ }^{19}$

So according to the behaviourist view, the exemplary behaviour by the executive board stipulated in the Code is about visibly demonstrating the values of the firm in executive actions like target setting, monitoring, agenda setting, resource allocation, all balancing between the short term and the long term, the selection, assessment and deselection of managers and employees. It is not about the 'tone at the top' as some popular management books will have it, but about specific executive action.

The behaviourist approach of shaping and changing culture can be rather fast in effects, but 'changes in behavior brought on by changes in incentives (monetary, and non-monetary, e.g. group membership) are superficial, they can be reversed as quickly and seamlessly as they

18. Bohmer R. M. J. \& Romney A. C. (2009). Performance Management at Intermountain Healthcare. Boston, MA: Harvard Business School.

19. Schein E. H. (1999). The Corporate Culture Survival Guide: Sense and Nonsense about Culture Change. San Francisco, CA: Jossey-Bass Publishers. 
have been brought on'. ${ }^{20}$ The behaviourist approach will be relevant in situations of below standard operations, high labour turnover, temporary jobs, part-time jobs, contractors, etc.

The school of cognitive psychology assumes that human behaviour results from an internalised script or scenario that specifies - for a given set of conditions and a given set of governing values-intended outcomes, as well as the actual behaviours required to produce those outcomes. ${ }^{21}$

This school assumes that to effect change in orientation (long-term value creation) and for this required behaviour, it is sufficient to intervene at the level of individuals, by educating these individuals in new insights, concepts and understanding. ${ }^{22}$ This insight we see in criterion 2 and 6 in the characteristics of a long-term value creation oriented organisation, acquiring new knowledge and investments in human capital through management development programmes.

This script can be thought to consist of two sources of valuation for defining goals and selecting means; maximising utility and abiding with moral duty. ${ }^{23}$ What knowledge and understanding is needed for maximising utility is acquired through example, education, experience and in a dynamically changing economy, through deep thinking about fundamental changes in the economy and participating in a knowledge ecology according to the principle of non sibi vivere, sed et aliis proficere. ${ }^{24}$ The stance, knowledge and understanding guiding moral behaviour, defining the worldview of individuals as relevant for setting long-term objectives, is internalised through a socialisation process. ${ }^{25}$ As the source of morality in society is the sphere of the civil society, not the sphere of government or the market, this socialisation process depends on the degree of participation of the individual in the sphere of the civil society, that is outside the sphere of the market. ${ }^{26}$ This insight questions whether the moral dimension of long-term value creation can be fostered by the values of the firm only. It might be, as some firms do, that the participation of employees in civic work, non-profit, charitable work, explicitly is valued and even in some cases supported in terms of time and resources.

20. Gardner H. (2004). Changing Minds: The Art and Science of Changing Our Own and Other People's Minds. Boston, MA: Harvard Business School Press, p. 58.

21. Argyris C. (2000). Flawed Advice and the Management Trap: How Managers Can Know When They're Getting Good Advice and When They're Not. New York: Oxford University Press.

22. Beer M., Eisenstat R. A. \& Spector B. (1990). The Critical Path to Corporate Renewal. Boston, MA: Harvard Business School Press.

23. Etzioni A. (1988). The Moral Dimension: Towards A New Economics. New York: The Free Press.

24. Martin R. L. (2007). The Opposable Mind: How Successful Leaders Win through Integrative Thinking. Boston, MA: Harvard Business School Press.

25. Etzioni 1998, p. 41.

26. Powelson J. P. (1998). The Moral Economy. Ann Arbor, MI: The University of Michigan Press; Sloterdijk P. (2004). Schäume. Frankfurt am Main: Suhrkamp; Sloterdijk P. (1999). Globen. Frankfurt am Main: Suhrkamp; Sloterdijk P. (1998). Blasen. Frankfurt am Main: Suhrkamp.
The cognitive science approach produces more stable, more robust cultures, including a proper design of the formal organisation, including a codification of the mission and values in the systems, processes and procedures of the organisation. As acknowledged in economic theory, economic growth is driven by new ideas, new concepts and reconceptualisation of industries, markets, business, organisation and products. Therefore, investing in human capital with a view on long-term value creation is congruent with economic growth. Due to the reflexive relationship between knowledge and the reality of markets, especially successful strategies and business models have a tendency to destroy themselves, requiring new concepts and ideas for long-term value creation, or in cybernetic terms, transformation of the business. However, Saul to Paul-type conversions of the mind are rare; it is difficult to change the mind when perspectives are held strongly, and publicly, and by individuals of rigid temperament. ${ }^{27}$ Unless according to Kohlberg's stages of moral development, the moral dimension in the script of the CEO has the upper hand over the dominant logic in the organisation about what works or not in business. ${ }^{28}$ This explains why CEOs with a view on long-term value creation have a tolerant style of leadership and foster an organic organisation and, given the final values, emphasise the role of knowledge and knowledge acquisition as a prerequisite for long-term value creation in a dynamic environment, requiring adaptation and innovation, that is epistemic values precede instrumental values like teamwork, transparency, etc.

Good CEOs follow, consciously or unconsciouly, both cognitive and behaviourist schools for shaping culture, understanding that most people need a consistent context to guide their behaviour. More importantly, both schools imply that shaping a culture requires more than values, exemplary behaviour and codes of conduct.

\section{An Appreciation of the Dutch Corporate Governance Code with Respect to How to Achieve Long-Term Value Creation}

The stipulation of the Code that firms should focus on longer term (sustainable) value creation is a noble objective and is supported by various insights with respect to the reconciliation of the private profit motive and the general interest. ${ }^{29}$ The value of long-term sustainable

27. Gardner 2004, p. 62.

28. Kohlberg L. (1969). Stage and sequence: the cognitive-developmental approach to socialization. In D. A. Goslin (Ed.), Handbook of Socialization: Theory and Research. New York: Rand McNally \& Corp.; Prahalad \& Krishnan 2008.

29. Barton D. (2011). Capitalism for the Long Term. Harvard Business Review, (March), 85-91, Dallas L. L. (2012). Short-terminism, the 
value creation can also be found in other codes, e.g. the Deutsche Corporate Governance Kodex.

Setting an objective for a firm is the responsibility of the executive board under the supervision of the supervisory board; the law or a code cannot mandate objectives to a firm. If an executive board decides for long-term value creation, and or long-term value creation is constitutionally the mission of the firm, its policies, actions and decisions need to be consistent and complete in view of best practices for business administration.

The suggestion in the Code that long-term value creation will be achieved through a vision, a strategy, a required culture and that this culture can be shaped by values, exemplary behaviour and a code of conduct, falls short compared to what is known to be needed for a firm to be robust on long-term (sustainable) value creation.

This might raise the question, in case of a difference of judgement between the executive board and the supervisory board whether the executive board has initiated proper and sufficient actions with respect to long-term value creation, the executive board can exculpate itself by invoking the suggestions in the Code with respect to what is needed for effective long-term value creation.

The Code is based on the principle of 'comply or explain'. Usually this principle is interpreted in a negative sense, to explain why specific provisions in the Code are not applied. It can be argued, based on the duty of care, that in specific situations the principle of 'comply or explain' need to be interpreted in a positive sense, that an executive board applies not just 'best practices' as stipulated in the Code, but 'better practices' to be found in firms that demonstrate effectively long-term value creation. To this also applies the rule in economics that a best practice is not a general, common practice in business and the market; a best practice is the known most efficient practice, even if applied by only a minority of leading firms.

Therefore, in case of differences of opinion with respect to effective policies for long-term value creation, neither the executive board nor the supervisory board should, or can, rely on the stipulations of the Code, but should abide by their moral duty, in order to serve the interests of the firm, to explore in the market, usually through the assistance of experts, what are the better practices in a leading firm to have effective long-term value creation.

\section{Conclusion}

The noble principle of long-term value creation requires more than a specific culture in the organisation of a firm; a holistic policy with respect to all dimensions of the organisation is needed to effectuate long-term value creation. Shaping a culture serving long-term value creation requires more specific administrative tools and policies than values, exemplary behaviour and codes of conduct. The simulacra nature of the concept of culture induces the risk that working on culture becomes a nonperformative language game, suggesting compliance with the Code, but no achievement of long-term value creation, nor the other objectives projected in the sign of culture by the Dutch Monitoring Commission. Immanuel Kant's principle sapere aude, dare to know, in combination with the duty of care, requires executives and members of supervisory board to understand culture beyond the word-symbol, but to see it as an element of the larger system and to see the constituent elements of the phenomenon of culture, in order to turn potential conflicts and disappointments into constructive, explorative learning debates and solutions. 